\title{
Clinical implications of progranulin in gastric cancer and its regulation via a positive feedback loop involving AKT and ERK signaling pathways
}

\author{
DONG YANG ${ }^{1,2}$, RUIDONG LI ${ }^{1}$, HUILI WANG ${ }^{1}$, JUNYE WANG $^{1}$, LEI HAN ${ }^{1}$, LIHUA PAN ${ }^{1}$, \\ XUEQIN LI ${ }^{1}$, QINGLI KONG ${ }^{1}$, GUIJUAN WANG ${ }^{1}$ and XIUJUN SU ${ }^{1}$ \\ ${ }^{1}$ Department of Oncology, Affiliated Hospital of Jining Medical University, Jining, Shandong 272029; \\ ${ }^{2}$ Department of Oncology, Jinan Central Hospital Affiliated to Shandong University, Jinan, Shandong 250013, P.R. China
}

Received November 2, 2016; Accepted August 24, 2017

DOI: $10.3892 / \mathrm{mmr} .2017 .7796$

\begin{abstract}
In previous years, progranulin (PGRN) has attracted increasing attention due to its oncogenic roles in several types of tumor. However, the clinical relevance of PGRN in gastric cancer remains to be elucidated. In the present study, 120 retrospective tissue samples were obtained from patients with primary gastric cancer, and the expression of PGRN was detected using immunohistochemistry. The results showed that 71 cases exhibited a high expression of PGRN, which was markedly higher than the 49 cases with a low expression of PGRN. Subsequent $\chi^{2}$ analysis confirmed for the first time, to the best of our knowledge, that a high level of PGRN was positively correlated with lymph node metastasis $(\mathrm{P}=0.048)$, lymphatic invasion $(\mathrm{P}=0.018)$ and advanced clinical stage $(\mathrm{P}=0.027)$. Survival analysis showed that PGRN was positively correlated with poorer overall survival (OS; $\mathrm{P}=0.0043$ ) and progression-free survival (PFS; $\mathrm{P}=0.0022$ ). Univariate and multivariate Cox regression analysis showed that PGRN and clinical stage had a significant effect on the OS and PFS of the patients with gastric cancer. In addition, cell experiments confirmed that extracellular PGRN promoted the intracellular expression of PGRN in a concentration-dependent manner in gastric cancer cells. The AKT and extracellular signal-regulated kinase signaling pathways were involved in the upregulation of intracellular PGRN induced by extracellular PGRN in MKN-45 and MGC-803 gastric cancer cells. Taken together, the results of the present study suggested that PGRN may be important in the progression and prognosis of gastric cancer, and that the expression of PGRN was regulated in a positive feedback loop. These findings enhance current knowledge regarding PGRN in tumors.
\end{abstract}

Correspondence to: Dr Junye Wang, Department of Oncology, Affiliated Hospital of Jining Medical University, 79 Guhuai Road, Jining, Shandong 272029, P.R. China

E-mail: junyewang1234@163.com

Key words: gastric cancer, progranulin, immunohistochemistry, overall survival, progression-free survival

\section{Introduction}

Despite the decline in the incidence of gastric cancer, it remains one of the most common malignant tumors worldwide and is one of the leading causes of cancer-associated mortality worldwide $(1,2)$. This is a result of malignant behaviors, including rapid progression, and ease of metastasis and recurrence, and the poor prognosis of patients with gastric cancer (3). In previous years, due to improvements in early diagnosis and the development of combined therapy, the mortality rates of patients with gastric cancer have declined to certain degree. However, for a substantial proportion of patients with progressive gastric cancer, the prognosis remains poor (4). Therefore, there is an urgent requirement to identify more effective targets to improve therapy outcomes.

Progranulin (PGRN) is a secretory protein. Previous studies have suggested that it is mainly expressed in specific neuron cells (5), immune cells (6), chondrocytes (7) and epithelial cells (8), mediating the prevention of neurodegeneration, wound healing and cartilage development (5-9). High expression levels of PGRN, and its correlation with tumor progression and poor prognosis, have been reported in different types of tumor, including breast cancer $(10,11)$, ovarian cancer $(12,13)$ and liver cancer (14). However, the role of PGRN in gastric cancer remains to be elucidated.

In the present study, the expression levels of PGRN in gastric cancer tissues were detected using immunohistochemistry (IHC), and PGRN was confirmed to correlate with lymph node metastasis, lymphatic invasion, advanced clinical stage and poor prognosis for the first time, to the best of our knowledge. In addition, investigation of the molecular mechanism showed that the level of PGRN in gastric cancer cells was regulated by extracellular PGRN via the AKT and extracellular signal-regulated kinase (ERK) signaling pathways in a positive feedback loop.

\section{Materials and methods}

Cell lines and cell culture. The MKN-45 and MGC-803 human gastric cancer cell lines were purchased from American Type Culture Collection (Manassas, VA, USA). These cell 


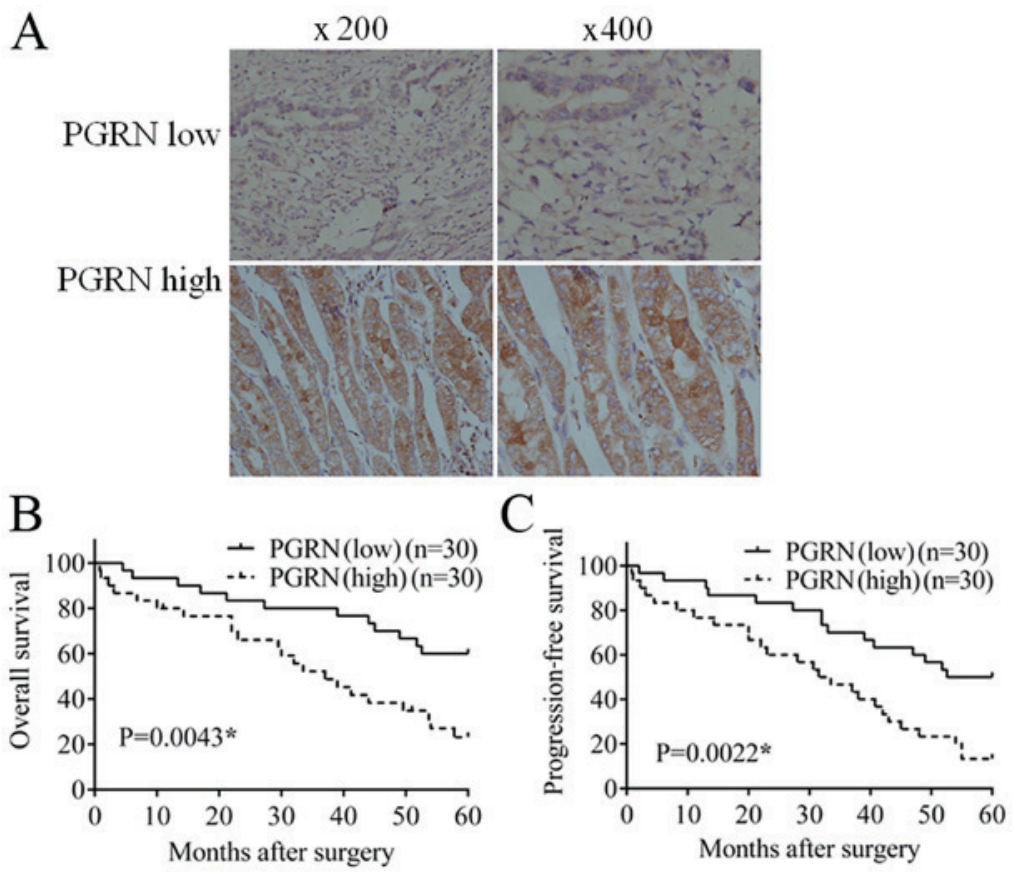

Figure 1. Expression of PGRN in gastric cancer tissues and its correlation with overall survival and progression-free survival rates. (A) Immunohistochemical staining of PGRN in gastric cancer tissues. (B) Comparison of overall survival rates between the PGRN low expression group and PGRN high expression group. (C) Comparison of progression-free survival rates between the PGRN low expression group and PGRN high expression group. PGRN, progranulin.

lines were cultured in RMPI-1640 medium (Gibco; Thermo Fisher Scientific, Inc., Waltham, MA, USA) supplemented with $10 \%$ fetal bovine serum (FBS; Gibco; Thermo Fisher Scientific, Inc.). All cells were cultured in $5 \% \mathrm{CO}_{2}$ at $37^{\circ} \mathrm{C}$.

To determine the underlying molecular mechanism of PGRN regulation, an AKT inhibitor (LY294002) and ERK inhibitor (U0126) were used. After resuspending in dimethyl sulfoxide, LY294002 or U0126 was added to medium at a final concentration of $50 \mu \mathrm{mol} / 1$ or $10 \mu \mathrm{mol} / 1$, respectively. Then, recombinant PGRN (rPGRN) was added and cells were cultured for 2 days.

$I H C$. Following approval from the review board and ethics committee, 120 retrospective primary gastric cancer tissue samples were collected from patients who accepted surgical treatment between 2007 and 2010 in Jinan Central Hospital Affiliated to Shandong University (Jinan, China). None of the patients received chemotherapy or radiotherapy prior to surgery. Follow-up was continued until 31st December 2015.

The tissue samples were cut into sections (3- $\mu \mathrm{m}$ thick) and incubated with primary antibodies against PGRN (1:400; cat no. ALX-804-737-C100, Enzo life science, Farmingdale, NY, USA) at $4^{\circ} \mathrm{C}$ overnight. Normal rabbit IgG, in place of primary antibodies, was used as a negative control. The sections were then incubated with HRP-conjugated goat anti-rabbit IgG polymer (cat no. 9902, Fuzhou Maixin Biotech Co., Ltd., Fuzhou, China) at room temperature for $30 \mathrm{~min}$ and stained with 3,3'-diaminobenzidin. The cell nuclei were stained using hematoxylin. The expression scores were evaluated by two independent pathologists simultaneously under a microscope (magnification, x400). The fraction of positively-stained tumor cells was evaluated using proportion scores $(0$, none; $1,<25 \%$; $2,26-75 \% ; 3,>75 \%)$. The intensity score represented the average staining intensity $(0$, none; 1 , weak; 2 , intermediate; 3 , strong). The expression of PGRN was evaluated by combining the proportion score and intensity score. Scores $\geq 4$ were considered as high expression and those $<4$ was considered as low expression.

Reverse transcription polymerase chain reaction (RT-PCR) analysis. Total RNA from the gastric cancer cells was extracted using TRIzol (Invitrogen; Thermo Fisher Scientific, Inc.). The PrimeScript RT-PCR kit (Takara Biotechnology Co., Ltd., Dalian, China) was used to synthesize cDNAs. The primers were as follows: PGRN, forward 5'-ATCTTTACCGTCTCA GGGACTT-3' and reverse 5'-CCATCGACCATAACACAG CAC-3'; GAPDH, forward 5'-AGAAGGCTGGGGCTCATT TG-3' and reverse 5'-AGGGGCCATCCACAGTCTTC-3'. The amplification mixture was as follows: $1.4 \mu \mathrm{l}$ cDNA, $1.6 \mu \mathrm{l}$ forward primer, $1.6 \mu \mathrm{l}$ reverse primer, $5.4 \mu 1$ double distilled $\mathrm{dH}_{2} \mathrm{O}$ and $10 \mu \mathrm{l}$ buffer was incubated at $94^{\circ} \mathrm{C}$ for $5 \mathrm{~min}$, followed by 30 cycles at $94^{\circ} \mathrm{C}$ for $30 \mathrm{sec}, 53^{\circ} \mathrm{C}$ for $30 \mathrm{sec}$, and $72^{\circ} \mathrm{C}$ for $30 \mathrm{sec}$, at last in $72^{\circ} \mathrm{C}$ for $5 \mathrm{~min}$. PCR products were electrophoretically separated on $1.0 \%$ agarose gels. The results were analyzed by Labwork software version 4.0 (UVP, Inc., Upland, CA, USA) (15).

Western blot analysis. Cells were washed twice in PBS and lysed in radioimmunoprecipitation assay buffer (cat no. P0013B, Beyotime Institute of Biotechnology, Haimen, China) containing $1 \%$ protease inhibitor. Protein concentration was measured by spectrophotometry (ND-1000; NanoDrop Technologies; Thermo Fisher Scientific, Inc.). A total of $200 \mu \mathrm{g}$ protein was loaded per well in 5\% acrylamide and separated by $10 \%$ separating gel and transferred onto a PVDF membrane (EMD Millipore, Billerica, MA, USA). The membrane was then incubated with the following primary antibodies at $4^{\circ} \mathrm{C}$ overnight: PGRN (cat no. ALX-804-737-C100, Enzo life 
Table I. Correlation between PGRN and clinical parameters of patients with gastric cancer.

\begin{tabular}{|c|c|c|c|c|c|}
\hline \multirow[b]{2}{*}{ Parameter } & \multirow[b]{2}{*}{$\begin{array}{l}\text { Cases } \\
\text { (n) }\end{array}$} & \multicolumn{2}{|c|}{ PGRN } & \multirow[b]{2}{*}{$\chi^{2}$-value } & \multirow[b]{2}{*}{ P-value } \\
\hline & & $\begin{array}{l}\text { Low } \\
\text { (n) }\end{array}$ & $\begin{array}{l}\text { High } \\
\text { (n) }\end{array}$ & & \\
\hline \multicolumn{6}{|l|}{ Age (years) } \\
\hline$\geq 60$ & 58 & 28 & 30 & \multirow{2}{*}{2.574} & \multirow{2}{*}{0.109} \\
\hline$<60$ & 62 & 21 & 41 & & \\
\hline \multicolumn{6}{|l|}{ Sex } \\
\hline Male & 86 & 36 & 50 & \multirow{2}{*}{0.133} & \multirow{2}{*}{0.716} \\
\hline Female & 34 & 13 & 21 & & \\
\hline \multicolumn{6}{|l|}{ Differentiation } \\
\hline High/moderate & 73 & 29 & 44 & \multirow{2}{*}{0.095} & \multirow{2}{*}{0.758} \\
\hline Poor & 47 & 20 & 27 & & \\
\hline \multicolumn{6}{|l|}{ Invasion depth } \\
\hline $\mathrm{T} 1 / \mathrm{T} 2$ & 34 & 18 & 16 & \multirow{2}{*}{2.879} & \multirow{2}{*}{0.090} \\
\hline T3/T4 & 86 & 31 & 55 & & \\
\hline \multicolumn{6}{|l|}{$\begin{array}{l}\text { Lymph node } \\
\text { metastasis }\end{array}$} \\
\hline+ & 62 & 20 & 42 & \multirow{2}{*}{3.904} & \multirow{2}{*}{$0.048^{\mathrm{a}}$} \\
\hline- & 58 & 29 & 29 & & \\
\hline \multicolumn{6}{|l|}{$\begin{array}{l}\text { Lymphatic } \\
\text { invasion }\end{array}$} \\
\hline+ & 83 & 28 & 55 & \multirow{2}{*}{5.614} & \multirow{2}{*}{$0.018^{\mathrm{a}}$} \\
\hline- & 37 & 21 & 16 & & \\
\hline \multirow{2}{*}{\multicolumn{6}{|c|}{$\begin{array}{l}\text { Vascular } \\
\text { invasion }\end{array}$}} \\
\hline & & & & & \\
\hline+ & 56 & 28 & 28 & \multirow{2}{*}{3.652} & \multirow{2}{*}{0.056} \\
\hline- & 64 & 21 & 43 & & \\
\hline \multicolumn{6}{|l|}{ Clinical stage } \\
\hline I-II & 47 & 25 & 22 & \multirow{2}{*}{4.884} & \multirow{2}{*}{$0.027^{\mathrm{a}}$} \\
\hline III & 73 & 24 & 49 & & \\
\hline
\end{tabular}

${ }^{\mathrm{a}} \mathrm{P}<0.05$ was considered to indicate statistical significance. PGRN, progranulin.

science); phosphorylated (p-)ERK (cat no. 2219-1, Epitomics, Burlingame, CA, USA); ERK (cat no. 12950, Cell Signaling Technology, Inc., Danvers, MA, USA); p-AKT (cat no. 2938, Cell Signaling Technology, Inc.); AKT (cat no. 4685, Cell Signaling Technology, Inc.); GAPDH (cat no. 10494-1-AP, Proteintech Group, Inc., Wuhan, China). This was followed by incubation with HRP-conjugated goat anti-rabbit-IgG (cat no. SA00001-2, 1:4,000, Proteintech Group, Inc.) at room temperature for $1 \mathrm{~h}$. Signals on the membrane were visualized using chemiluminescence reagents (EMD Millipore).

Statistical analysis. All data are expressed as the mean \pm standard deviation. SPSS 11.0 software, (SPSS, Inc., Chicago, IL, USA) was used for analysis. The correlation of PGRN with clinical parameters was analyzed using the $\chi^{2}$ test. Survival curves were drawn using the Kaplan-Meier method, and means were compared using the log-rank test. Cox regression analysis was performed to confirm potential prognostic factors of gastric cancer. The differences between two groups were analyzed using Student's two-tailed t-test. $\mathrm{P}<0.05$ was considered to indicate a statistically significant difference.

\section{Results}

High expression of PGRN is positively correlated with lymph node metastasis, lymphatic invasion and advanced clinical stage. As shown in Fig. 1A, PGRN was mainly expressed in the cytoplasm of tumor cells, with sporadic weak staining also present in the tumor mesenchyme. The cases were divided into two groups according to different expression levels of parenchymal PGRN; there were 49 cases with low expression of PGRN, which was markedly lower than the 71 cases with high expression of PGRN.

As shown in Table I, in the PGRN low expression group, only 20 of the 49 cases exhibited lymph node metastasis, which was significantly lower than the high expression group, in which 42 of the 71 cases exhibited lymph node metastasis. In addition, 28 of the 49 cases exhibited lymphatic invasion, which was significantly lower than the high expression group, in which 55 of the 71 cases exhibited lymphatic invasion. A total of 24 of the 49 cases were at clinical stage III, which was significantly lower than the 49 of 71 cases in the group expressing a high level of PGRN. The results of the $\chi^{2}$ test showed that PGRN was positively correlated with lymph node metastasis $(\mathrm{P}=0.048)$, lymphatic invasion $(\mathrm{P}=0.018)$ and clinical stage $(\mathrm{P}=0.027)$.

PGRN is positively correlated with poor prognosis. In 30 follow-up cases with low expression of PGRN, 12 cases succumbed to mortality and the overall survival (OS) rate was $60 \%$; 15 cases showed disease progression, and the progression-free survival (PFS) rate was $50 \%$. In 30 follow-up cases with high expression of PGRN, 22 cases succumbed to mortality and the OS rate was $26.7 \%$, which was substantially lower, compared with that in the low expression group. There were 26 cases of disease progression and the PFS rate was $13.3 \%$, which was substantially lower, compared with that in the low expression group. Statistical analysis confirmed that the OS (Fig. 1B; $\mathrm{P}=0.0043$ ) and PFS (Fig. 1C; $\mathrm{P}=0.0022$ ) in the low PGRN group were significantly higher than the rates in the high PGRN group.

Regression analysis for potential prognostic factors. To confirm the potential prognostic factors for gastric cancer in the present study, Cox regression analysis was performed. The univariate Cox regression analysis showed that the expression of PGRN $(\mathrm{P}=0.002)$ and clinical stage $(\mathrm{P}<0.001)$ had a significant effect on the OS rate of the patients with gastric cancer (Table II). The PGRN $(\mathrm{P}=0.003)$ and clinical stage $(\mathrm{P}=0.004)$ also had a significant effect on the PFS rate of the patients with gastric cancer (Table III).

To further ascertain the potential prognostic factors, multivariate Cox regression analysis was also performed and showed that the expression of PGRN $(\mathrm{P}=0.048)$ and clinical stage $(\mathrm{P}=0.001)$ had a significant effect on the OS rates of 
Table II. Univariate and multivariate analyses of factors affecting OS rates in patients with gastric cancer.

\begin{tabular}{|c|c|c|c|c|c|c|}
\hline \multirow[b]{2}{*}{ Variable } & \multicolumn{3}{|c|}{ Univariate analysis } & \multicolumn{3}{|c|}{ Multivariate analysis } \\
\hline & $\mathrm{RR}$ & $95 \% \mathrm{CI}$ & P-value & $\mathrm{RR}$ & $95 \% \mathrm{CI}$ & P-value \\
\hline PGRN & 2.952 & $1.468-5.937$ & $0.002^{\mathrm{a}}$ & 2.258 & $1.008-5.056$ & $0.048^{\mathrm{a}}$ \\
\hline Lymph node involvement & 1.158 & $0.602-2.228$ & 0.660 & 1.061 & $0.533-2.109$ & 0.867 \\
\hline Lymphatic invasion & 1.842 & $0.887-3.826$ & 0.101 & 1.247 & $0.532-2.922$ & 0.611 \\
\hline Vascular invasion & 1.141 & $0.591-2.203$ & 0.695 & 0.923 & $0.463-1.839$ & 0.820 \\
\hline Differentiation & 1.547 & $0.803-2.98$ & 0.192 & 1.549 & $0.753-3.185$ & 0.234 \\
\hline Clinical stage & 3.783 & $1.847-7.75$ & $<0.001^{\mathrm{a}}$ & 3.493 & $1.691-7.218$ & $0.001^{\mathrm{a}}$ \\
\hline
\end{tabular}

${ }^{a} \mathrm{P}<0.05$ was considered to indicate statistical significance. RR, relative risk; 95\% CI, 95\% confidence interval; OS, overall survival; PRGN, progranulin.

Table III. Univariate analysis and multivariate analysis of factors affecting PFS rates in patients with gastric cancer.

\begin{tabular}{|c|c|c|c|c|c|c|}
\hline \multirow[b]{2}{*}{ Variable } & \multicolumn{3}{|c|}{ Univariate analysis } & \multicolumn{3}{|c|}{ Multivariate analysis } \\
\hline & $\mathrm{RR}$ & $95 \% \mathrm{CI}$ & P-value & $\mathrm{RR}$ & $95 \% \mathrm{CI}$ & P-value \\
\hline PGRN & 2.626 & $1.382-4.988$ & $0.003^{\mathrm{a}}$ & 2.215 & $1.075-4.562$ & $0.031^{\mathrm{a}}$ \\
\hline Lymph node involvement & 1.220 & $0.660-2.256$ & 0.526 & 1.043 & $0.552-1.973$ & 0.896 \\
\hline Lymphatic invasion & 1.909 & $0.971-3.755$ & 0.061 & 1.287 & $0.592-2.797$ & 0.524 \\
\hline Vascular invasion & 1.022 & $0.553-1.888$ & 0.946 & 0.886 & $0.466-1.684$ & 0.711 \\
\hline Differentiation & 1.262 & $0.682-2.334$ & 0.458 & 1.398 & $0.721-2.708$ & 0.321 \\
\hline Clinical stage & 2.540 & $1.348-4.786$ & $0.004^{\mathrm{a}}$ & 2.474 & $1.300-4.707$ & $0.006^{\mathrm{a}}$ \\
\hline
\end{tabular}

${ }^{a} \mathrm{P}<0.05$ considered to indicate statistical significance. RR, relative risk; 95\% CI, 95\% confidence interval; PFS, progression-free survival; PRGN, progranulin.

patients with gastric cancer (Table II); PGRN ( $\mathrm{P}=0.031)$ and clinical stage $(\mathrm{P}=0.006)$ also had significant effects on the PFS rates of patients with gastric cancer (Table III). Lymph node involvement, lymphatic invasion, vascular invasion and differentiation had no prognostic significance, when evaluated using univariate Cox regression analysis and multivariate Cox regression analysis.

Extracellular PGRN promotes the intracellular expression of PGRN via the AKT and ERK signaling pathways. As shown in Fig. 2, when stimulated with different concentrations of recombinant PGRN (rPGRN) for 2 days, the expression of intracellular PGRN was significantly upregulated at the mRNA level in the MKN-45 and MGC-803 cells (Fig. 2A and $\mathrm{B}$ ) in a concentration-dependent manner. The same was true of the protein levels (Fig. 2C and D). This confirmed the positive feedback regulatory mechanism of PGRN in gastric cancer cells.

Subsequent investigation into the molecular mechanism underlying the above process showed that the phosphorylation of EKT was activated by rPGRN in the MKN-45 (Fig. 3A) and MGC-803 (Fig. 3B) cells, and the same was observed for the phosphorylation of AKT (Fig. 3C and D). The ERK inhibitor (U0126) and AKT inhibitor (LY294002) abrogated the upregulation of intracellular PGRN induced by rPGRN in the MKN-45 (Fig. 3A and C) and MGC-803 (Fig. 3B and D) cells. This confirmed the roles of AKT and ERK in the positive feedback regulation of the expression of PGRN.

\section{Discussion}

The PGRN gene is localized on human chromosome 17 and the encoding region is composed of 12 exons. PGRN protein weighs $68.5 \mathrm{kDa}$ and is composed of 7.5 tandem repeats, which are rich in serine (16). In previous years, the importance of PGRN has been widely reported in different types of tumor. In 2014, Edelman et al reported that PGRN was expressed at high levels in non-small cell lung carcinoma (NSCLC) tissues and was correlated with poor OS and PFS rates in patients with NSCLC (17). In our previous study, PGRN not only promoted the proliferation and angiogenesis of colorectal cancer, but also was positively correlated with lymph node metastasis, advanced clinical stage and poor PFS rates (18).

Cancer progression is a complex process and its prognosis can be affected by different factors. Patients at an advanced clinical stage usually have a poorer prognosis, compared with patients at an early stage. In the present study, it was confirmed that PGRN and clinical stage had potential effects on the prognosis of patients with gastric cancer through Cox 


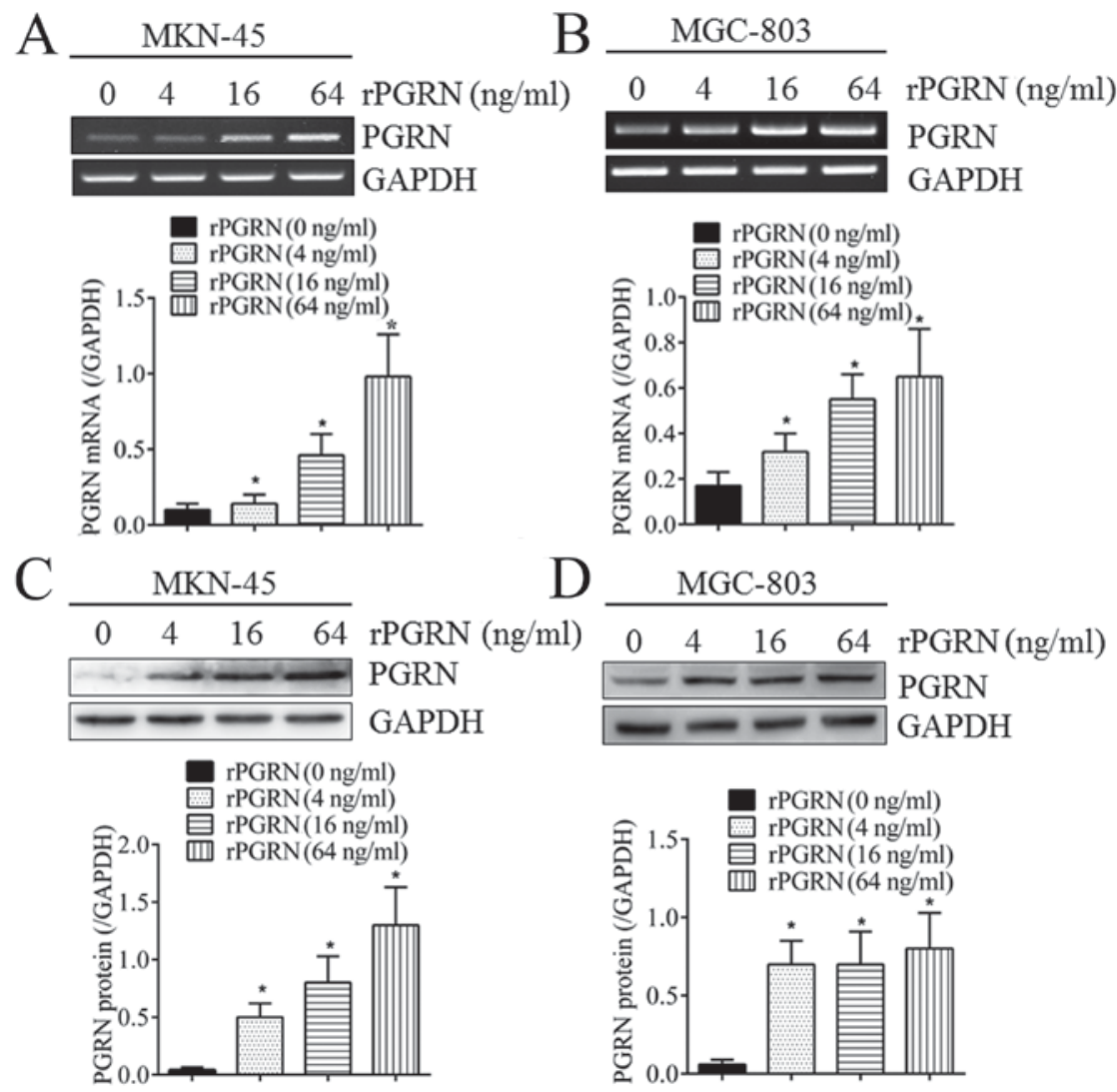

Figure 2. Extracellular PGRN promotes the intracellular expression of PGRN. Following stimulation with rPGRN, intracellular mRNA expression of PGRN was upregulated in the (A) MKN-45 cells and (B) MGC-803 cells. Intracellular protein expression of PGRN was also upregulated in the (C) MKN-45 cells and (D) MGC-803 cells. PGRN, progranulin; rPGRN, recombinant PGRN. "P<0.05 vs. cells stimulated by rPGRN (0 ng/ml).

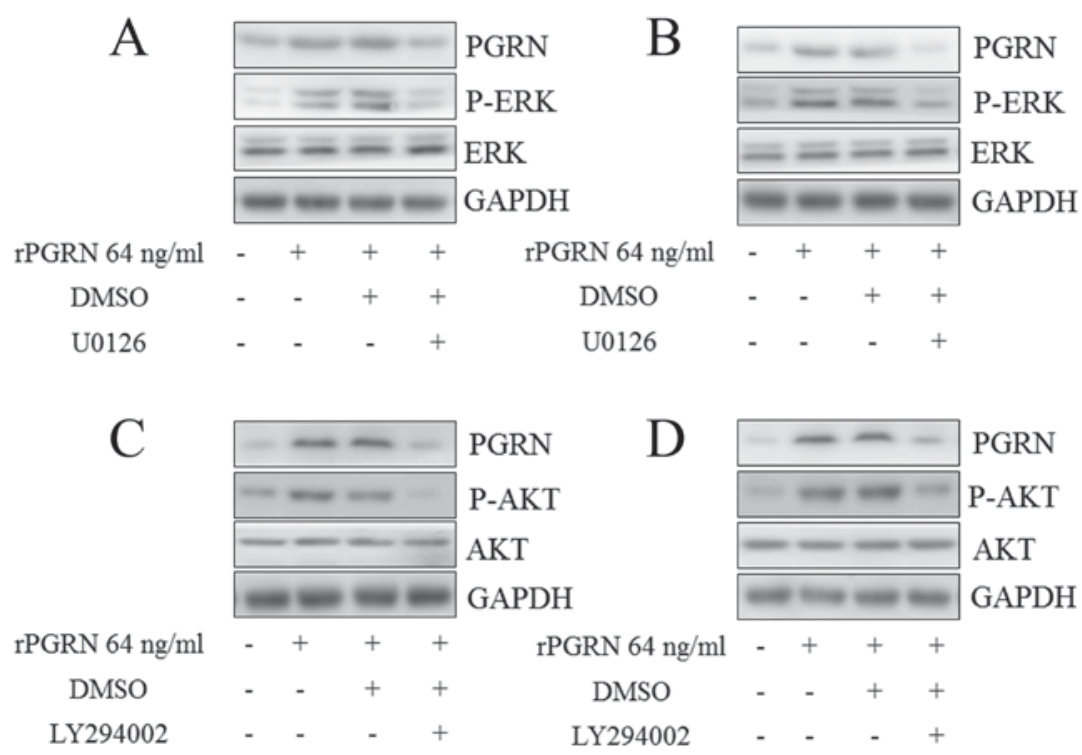

Figure 3. AKT and ERK are involved in the expression of intracellular PGRN induced by extracellular PGRN. Following the addition of rPGRN, the phosphorylation of ERK was activated in the (A) MKN-45 cells and (B) MGC-803 cells. The phosphorylation of AKT was also activated in the (C) MKN-45 cells and (D) MGC-803 cells. ERK inhibitor (U0126) abrogated the intracellular expression of PGRN induced by rPGRN in the (A) MKN-45 cells and (B) MGC-803 cells. AKT inhibitor (LY294002) abrogated the intracellular expression of PGRN induced by rPGRN in the (C) MKN-45 cells and (D) MGC-803 cells. PGRN, progranulin; rPGRN, recombinant PGRN; ERK, extracellular signal-regulated kinase; p-, phosphorylated.

regression analysis. This evidence supporting the effects of PGRN and clinical stage on the prognosis of patients with gastric cancer emphasizes the importance of early screening and treatment. Lymph node involvement, lymphatic invasion, vascular invasion and differentiation had no significant effects in the present study, however, it is not possible to dismiss the importance of these factors in cancer progression and prognosis. The present study included a limited number of cases 
and a study comprising an increased number of cases may provide different results.

Until now, studies investigating the roles of PGRN in gastric cancer have been limited. In 2011, Wang et al reported that PGRN was expressed at a high level in gastric cancer tissue, however, no further retrospective analysis or cell experiments were performed (19). In the present study, the expression of PGRN in gastric cancer was examined, and it was confirmed that PGRN was positively correlated with lymph node metastasis, lymphatic invasion, advanced clinical stage, and poor OS and PFS rats in patients with gastric cancer. This confirmed the importance of PGRN in the progression and prognosis of gastric cancer. This was consistent with the tumor-promoting roles of PGRN reported in previous studies. However, there were limitations in the present study. Only 120 cases were enrolled in limited quantities, and the majority of cases were from local residents with regional patient information. This limited number of cases and regional data restrict the universality of the results. Multi-center and larger sample clinical trials are likely to improve the validity of the results.

As a secretory protein, under the guidance of signaling peptides, PGRN is secreted to the outside of cells and can regulate intracellular gene expression through binding to corresponding receptors on cell membranes in an autocrine or paracrine manner. In 2016, Liu et al reported that rPGRN promoted the expression of Cyclin-B1 and Cyclin-D1 in HepG2 hepatocellular carcinoma cells, resulting in cell growth (20). In our previous study, PGRN was shown to promote the expression of Ki67 and vascular endothelial growth factor A in colorectal cancer cells (21). However, whether PGRN regulated its expression in a positive feedback loop remained unclear. In the present study, it was confirmed that extracellular rPGRN efficiently promoted the intracellular expression of PGRN in MKN-45 and MGC-803 cells. This suggested that PGRN in patient blood may affect the expression of PGRN in tumor cells and, leading to tumor cells secreting increased PGRN into the blood, eventually resulting in high expression levels of PGRN in the tumor and blood, offering potential as a marker of tumor progression. Although the clinical implication of PGRN in the blood has been reported in several types of cancer, including breast cancer (22) and NSCLC (17), the results of the present study indicate the importance of PGRN in the circulation from another perspective.

A more detailed understanding of the molecular mechanism underlying the positive feedback regulation of PGRN is likely to improve knowledge of the role of PGRN in tumors. The AKT and ERK signaling pathways have been commonly investigated downstream targets of PGRN in several types of tumor (23-25). ERK is also a crucial signal target, which is responsible for the expression of PGRN induced by interleukin-6 in hepatocellular carcinoma cells (20). In the present study, it was found that extracellular PGRN efficiently promoted the intracellular expression of PGRN via the AKT and ERK signaling pathways. These results, together with those of the previous reports, provide sufficient evidence supporting the close correlation of ERK and AKT signaling pathways with the expression and functions of PGRN in cancer.

In conclusion, the present study elucidated the clinical implication of PGRN in the progression and prognosis of gastric cancer using IHC analysis. In addition, it was confirmed that PGRN regulated its own expression in a positive feedback loop via the AKT and ERK signaling pathways. These results improve current understanding of the role of PGRN in cancer and indicate a novel effective target for gastric cancer therapy.

\section{References}

1. Vohlonen I, Pukkala E, Malila N, Härkönen M, Hakama M, Koistinen V and Sipponen P: Risk of gastric cancer in Helicobacter pylori infection in a 15 -year follow-up. Scand $\mathrm{J}$ Gastroenterol 51: 1159-1164, 2016.

2. Hafez NH and Tahoun NS: Expression of cyclooxygenase 2 and vascular endothelial growth factor in gastric carcinoma: Relationship with clinicopathological parameters. J Egypt Natl Canc Inst 28: 149-156, 2016.

3. Li P, Sun D, Li X, He Y, Li W, Zhao J, Wang Y, Wang H and $\mathrm{X}$ in Y: Elevated expression of Nodal and YAP1 is associated with poor prognosis of gastric adenocarcinoma. J Cancer Res Clin Oncol 142: 1765-1773, 2016.

4. Yoshino S, Nishikawa K, Morita S, Takahashi T, Sakata K, Nagao J, Nemoto H, Murakami N, Matsuda T, Hasegawa $\mathrm{H}$, et al: Randomised phase III study of S-1 alone versus S-1 plus lentinan for unresectable or recurrent gastric cancer (JFMC36-0701). Eur J Cancer 65: 164-171, 2016.

5. Suzuki M and Nishiahara M: Granulin precursor gene: A sex steroid-inducible gene involved in sexual differentiation of the rat brain. Mol Genet Metab 75: 31-37, 2002.

6. Zhu J, Nathan C, Jin W, Sim D, Ashcroft GS, Wahl SM, Lacomis L, Erdjument-Bromage H, Tempst P, Wright CD and Ding A: Conversion of proepithelin to epithelins: Roles of SLPI and elastase in host defense and wound repair. Cell 111: 867-878, 2002.

7. Tang W, Lu Y, Tian QY, Zhang Y, Guo FJ, Liu GY, Syed NM, Lai Y, Lin EA, Kong L, et al: The growth factor progranulin binds to TNF receptors and is therapeutic against inflammatory arthritis in mice. Science 332: 478-484, 2011.

8. De Muynck L and Van Damme P: Cellular effects of progranulin in health and disease. J Mol Neurosci 45: 549-560, 2011.

9. Liu CJ and Bosch X: Progranulin: A growth factor, a novel TNFR ligand and a drug target. Pharmacol Ther 133: 124-132, 2012.

10. Swamydas M, Nguyen D, Allen LD, Eddy J and Dréau D: Progranulin stimulated by LPA promotes the migration of aggressive breast cancer cells. Cell Commun Adhes 18: 119-130, 2011.

11. Abrhale T, Brodie A, Sabnis G, Macedo L, Tian C, Yue B and Serrero G: GP88 (PC-Cell derived growth factor, progranulin) stimulates proliferation and confers letrozole resistance to aromatase overexpressing breast cancer cells. BMC Cancer 11: 231, 2011.

12. Diaz-Cueto L, Arechavaleta-Velasco F, Diaz-Arizaga A, Dominguez-Lopez $\mathrm{P}$ and Robles-Flores $\mathrm{M}$ : PKC signaling is involved in the regulation of progranulin (acrogranin/PC-cell-derived growth factor/granulin-epithelin precursor) protein expression in human ovarian cancer cell lines. Int J Gynecol Cancer 22: 945-950, 2012.

13. Carlson AM, Maurer MJ, Goergen KM, Kalli KR, Erskine CL, Behrens MD, Knutson KL and Block MS: Utility of progranulin and serum leukocyte protease inhibitor as diagnostic and prognostic biomarkers in ovarian cancer. Cancer Epidemiol Biomarkers Prev 22: 1730-1735, 2013.

14. Cheung PF, Cheng CK, Wong NC, Ho JC, Yip CW, Lui VC, Cheung AN, Fan ST and Cheung ST: Granulin-epithelin precursor is an oncofetal protein defining hepatic cancer stem cells. PLoS One 6: e28246, 2011.

15. Gao J, Liu D, Li J, Song Q and Wang Q: Effect of STK17A on the sensitivity of ovarian cancer cells to paclitaxel and carboplatin. Oncol Lett 12: 1107-1112, 2016.

16. Hu Y, Xiao H, Shi T, Oppenheim JJ and Chen X: Progranulin promotes tumour necrosis factor-induced proliferation of suppressive mouse $\mathrm{CD} 4^{+} \mathrm{Foxp}^{+}$regulatory $\mathrm{T}$ cells. Immunology 142: 193-201, 2014.

17. Edelman MJ, Feliciano J, Yue B, Bejarano P, Ioffe O, Reisman D, Hawkins D, Gai Q, Hicks D and Serrero G: GP88 (progranulin): A novel tissue and circulating biomarker for non-small cell lung carcinoma. Hum Pathol 45: 1893-1899, 2014. 
18. Dong T, Yang D, Li R, Zhang L, Zhao H, Shen Y, Zhang X, Kong B and Wang L: PGRN promotes migration and invasion of epithelial ovarian cancer cells through an epithelial mesenchymal transition program and the activation of cancer associated fibroblasts. Exp Mol Pathol 100: 17-25, 2016.

19. Wang H, Sun Y, Liu S, Yu H, Li W, Zeng J, Chen C and Jia J: Upregulation of progranulin by helicobacter pylori in human gastric epithelial cells via p38MAPK and MEK1/2 signaling pathway: Role in epithelial cell proliferation and migration. FEMS Immunol Med Microbiol 63: 82-92, 2011.

20. Liu F, Zhang W, Yang F, Feng T, Zhou M, Yu Y, Yu X, Zhao W, Yi F, Tang W and Lu Y: Interleukin-6-stimulated progranulin expression contributes to the malignancy of hepatocellular carcinoma cells by activating mTOR signaling. Sci Rep 6: 21260, 2016.

21. Yang D, Wang LL, Dong TT, Shen YH, Guo XS, Liu CY, Liu J, Zhang P, Li J and Sun YP: Progranulin promotes colorectal cancer proliferation and angiogenesis through TNFR2/Akt and ERK signaling pathways. Am J Cancer Res 5: 3085-3097, 2015.
22. Tkaczuk KR, Yue B, Zhan M, Tait N, Yarlagadda L, Dai H and Serrero G: Increased circulating level of the survival factor GP88 (progranulin) in the serum of breast cancer patients when compared to healthy subjects. Breast Cancer (Auck1) 5: 155-162, 2011.

23. He Z, Ismail A, Kriazhev L, Sadvakassova G and Bateman A: Progranulin (PC-cell-derived growth factor/acrogranin) regulates invasion and cell survival. Cancer Res 62: 5590-5596, 2002.

24. Kamrava M, Simpkins F, Alejandro E, Michener C, Meltzer E and Kohn EC: Lysophosphatidic acid and endothelin-induced proliferation of ovarian cancer cell lines is mitigated by neutralization of granulin-epithelin precursor (GEP), a prosurvival factor for ovarian cancer. Oncogene 24: 7084-7093, 2005.

25. Ong $\mathrm{CH}$ and Bateman A: Progranulin (granulin-epithelin precursor, PC-cell derived growth factor, acrogranin) in proliferation and tumorigenesis. Histol Histopathol 18: $1275-1288,2003$. 